\title{
La enseñanza del español en Brasil: Centroamérica, la región desconocida. Estudio de un caso
}

\author{
Teaching Spanish in Brazil: Central America the unknown region \\ NuRIa RodríGUEZ VARgas \\ Instituto de Estudios Latinoamericanos (IDELA) \\ Universidad Nacional, Costa Rica
}

\section{Resumen}

El presente artículo muestra los resultados de un estudio de caso realizado en el plan de estudios de la Licenciatura en Letras -Español del Departamento de Lenguas y Literaturas Extranjeras de la Universidad Federal de Santa Catarina, Brasil. Mediante un enfoque cualitativo, se profundizó en las experiencias, perspectivas, y opiniones de estudiantes y profesores del programa, con el objetivo de determinar el conocimiento sobre las manifestaciones culturales y arte de la región centroamericana.

Palabras clave: enseñanza de español, la región centroamericana, Brasil, lusoparlantes, Licenciatura en Letras-Español

\section{Abstract}

This article shows the results of a case study carried out in the curriculum of the program of Spanish Language and Literature of the Department of Foreign Languages and Literatures at the Federal University of Santa Catarina, Brazil. Through a qualitative approach, the experiences, perspectives, and opinions of students and professors of the program are deepened, with the objective of determining the level of knowledge about the cultural and art manifestations of the Central American region.

Keywords: teaching of Spanish, Central American region, Brazil, Portuguese speakers, Bachelor of Arts-Spanish 


\section{Introducción}

$\mathrm{E}$ 1 presente artículo describe el proceso y muestra los resultados de una investigación teórico-práctica realizada en la ciudad de Florianópolis, Brasil. Consistió en un proceso de observación sobre el desarrollo de la enseñanza del español dentro del sistema del Departamento de Lenguas y Literaturas Extranjeras (DLLE) de la Universidad Federal de Santa Catarina. El objetivo fue evaluar la importancia que los profesores brasileños le atribuyen al conocimiento de la cultura hispanoamericana y, en especial, de la región centroamericana.

A tono con lo anterior, planteé la siguiente interrogante para el desarrollo de la investigación: ¿Qué conocimiento de la cultura y del arte centroamericano manejan los estudiantes del programa Licenciatura en Letras-Español del Departamento de Lenguas y Literaturas Extranjeras (DLLE) de la Universidad Federal de Santa Catarina? Para recabar datos importantes, se aplicaron cuestionarios, se hicieron entrevistas y se realizaron talleres y clases, en función de saber la opinión, conocer las inquietudes de los estudiantes $\mathrm{y}$, al mismo tiempo, suministrar información sobre Centroamérica que pudiera ser de interés.

En la metodología de investigación, se utilizó un enfoque cualitativo, basado en la observación y en la descripción. La investigación cualitativa es "aquella que produce datos descriptivos: las propias palabras de las personas, habladas o escritas, y la conducta observable" (Taylor y Boddan, 1986, p. 20). Por otra parte, el investigador cualitativo debe ser sensible a los efectos que él mismo cause sobre los individuos que son objeto de estudio y trata de comprender a las personas dentro del marco de referencia de ellas mismas.

Se buscó comprender la perspectiva de los participantes, estudiantes y profesores; profundizar en sus experiencias, perspectivas, opiniones, visión de mundo y cómo perciben su realidad en su ambiente natural y en relación con su contexto. El enfoque cualitativo podría definirse como un conjunto de prácticas interpretativas que dan visibilidad al mundo, lo transforman y lo convierten en una serie de representaciones en forma de observaciones, anotaciones, grabaciones y documentos. Además, es naturalista porque estudia los objetos y los seres vivos en sus contextos o ambientes naturales, e interpretativo, pues intenta encontrar más sentido a los fenómenos en términos de los significados que las personas les otorguen (Hernández Sampieri, 2010, p. 10).

De acuerdo con lo anterior, la metodología utilizada estuvo encaminada en la obtención de datos que permitieran determinar la visión y conocimientos sobre la región centroamericana. Como parte del método, se realizó un trabajo de campo que consistió en el desplazamiento al lugar de estudio, la investigación, el examen y registro de los fenómenos sociales, culturales, lingüísticos y didácticos, mediante la observación y participación directa, y la inmersión en la vida educativa y académica. Se observaron, clasificaron y analizaron los hechos e interpretaron los datos obtenidos.

Para lograr el propósito de la investigación, estuve durante un mes (entre los meses de marzo y abril del año 2014) en la ciudad de Florianópolis, capital del Estado de Santa Catarina, en el Campus Universitario Reitor João David 
Ferreira Lima, en el Centro de Comunicación y Expresión (CCE), del Departamento de Lengua y Literatura Extranjera (DLLE). Realicé observaciones de clases y apliqué talleres en los grupos de las siguientes profesoras: Dra. Oliveira, en el curso de Español III; Msc. Parrini Ferreira, curso de Español VII; y Msc. Teixeira Saldanha, curso de Español I. Además, recabé información proveniente de los estudiantes de los respectivos cursos, por medio del cuestionario y la entrevista informal.

Durante la primera semana de investigación indagué en el contexto educativo y administrativo del Departamento de Lenguas y Literatura Extranjeras (DLLE). En este, se ofrecen bachilleratos y licenciatura en italiano, francés, alemán, inglés y español. En relación con esta última lengua, el Departamento ofrece la Licenciatura en Letras-Español, la cual tiene una duración de cuatro años (8 semestres o fases). El programa se divide en cursos de lingüística aplicada y literatura hispánica. Los estudiantes tienen dos salidas profesionales al término de las ocho fases: una es graduarse con el bachillerato, para lo cual deben escribir y presentar una tesina sobre algún tema relacionado con lingüística aplicada o literatura. Con este certificado, su campo laboral se abre a la traducción, revisión textual, o algún tipo de labor relacionada con el campo turístico. La otra salida es terminar la licenciatura, que incluye una carga académica de cursos de didáctica y pedagogía, además de una práctica profesional en un centro de educativo. Con la aprobación de todos los cursos del programa y la práctica, los estudiantes están certificados para enseñar en los centros de educación primaria como secundaria, tanto en el sector público como privado.
Por otra parte, también se ofrece la Licenciatura en Letras-Español modalidad a distancia. Al respecto, la Dra. Leandra Oliveira señaló que por el decreto 5622, del 19 de octubre de 2005 , artículo 5, se establece que el diploma de los graduados de la Licenciatura en Letras-Español a Distancia tiene la misma validez que la modalidad presencial en todo el país. Este forma parte del programa de Educación a Distancia de la Universidad Federal de Santa Catarina (EAD-UFSC) (João, 2010, pp.15-43). Esta iniciativa pertenece al Sistema de Educación Abierta de Brasil (UAB), creado por el decreto 5800, del 8 de junio del 2006. Tiene como objetivo el desarrollo y la expansión de la Educación a Distancia de nivel Superior. La idea es llevar educación gratuita y de calidad a los municipios que no tienen acceso a cursos de Educación Superior. Con esto se pretende aumentar la tasa de escolarización en el país suramericano.

En las semanas siguientes desarrollé, en los niveles de Español I, III y VII, clases tipo taller que incluían manifestaciones artísticas centroamericanas: poema, cuento, canciones y películas, como una manera de acercar e interesar al estudiante en la cultura de la región. Por otra parte, en las horas posteriores a las clases, hubo un acercamiento dialógico con los estudiantes, especialmente los que estaban interesados en continuar la salida profesional de la Licenciatura con el fin de ser docentes en el sistema de educación primaria y secundaria. Los estudiantes externaron sus opiniones con respecto al programa y a sus expectativas profesionales y laborales. Remarcaron el interés de estudiar más aspectos culturales de todos los países hispanoamericanos. 
Además, evidenciaron un escaso o casi nulo conocimiento de la región centroamericana, aspecto que profundizaré más adelante. Sin embargo, hubo un visible interés en descubrir un espacio geográfico y cultural casi totalmente desconocido.

\section{Aproximaciones al concepto de cul- tura y de Centroamérica}

La enseñanza de una lengua implica muchos factores por considerar, por ejemplo, los métodos y técnicas pedagógicas, la formación de los profesores, los recursos didácticos, el desarrollo de las habilidades auditiva, oral, lectora y de escritura. La quinta habilidad, la cultural, es de vital importancia a la hora de aprender y enseñar una lengua extranjera.

En este sentido, la investigación se enfocó en el desarrollo de la habilidad cultural en el proceso de enseñanza y aprendizaje del español en el contexto brasileño. Parto de la idea de que no se puede aprender una lengua sin estudiar y profundizar en la cultura de la cual nació; lengua y cultura son indivisibles, y una explica a la otra. En esta línea, considero que en el caso de la enseñanza del español en Brasil fue de vital importancia abocarse a referencias culturales hispanoamericanas, por medio de la historia, arte, costumbres, tradiciones y variantes lingüísticas de nuestros países.

La Real Academia Española de la Lengua (RAE) da varias definiciones de cultura. Primero, como un conjunto de conocimientos que permite a alguien desarrollar su juicio crítico; luego, como el conjunto de modos de vida y costumbres, conocimientos y grados de desarrollo artístico, científico, industrial en una época o grupo social; también, como culto religioso y como conjunto de manifestaciones en que se expresa la vida tradicional de un pueblo.

La definición de cultura es una tarea extensa, puesto que el concepto ha evolucionado y se ha transformado a lo largo de los años; existen muchas definiciones de cultura según el enfoque que interese, así podría ser desde la filosofía, la psicología, la estética y la antropología. En ocasiones, se asocia a las manifestaciones artísticas y en otros casos a la cultura popular.

Por la naturaleza de la investigación, me aboqué al concepto de cultura en el sentido antropológico, "[...] es decir, como modo de vida y visión de mundo, que surge y se configura en las condiciones materiales y simbólicas propias de una formación social concreta [...] se entiende la cultura como un proceso dinámico, en constante construcción, que tiene ciertas dimensiones más permanentes y estables que otras [...] la cultura no se reduce a las expresiones de las bellas artes y las letras, aunque estas se incluyen en su esfera de denotación" (Cuevas Molina, 2012, pp. 11-12).

Ligado al concepto de cultura se encuentra el término Centroamérica, un reducido espacio geográfico rico en manifestaciones culturales y con una historia compleja. Se podría hablar de campo o campos culturales con elementos diferenciados o comunes dependiendo del momento histórico (Cuevas Molina, 2012, pp. 12-14).

Así, a nivel geográfico e histórico, existen diversas clasificaciones. Se llama Centroamérica a las cinco naciones que juntas se independizaron de España en 1821 (Guatemala, El Salvador, Honduras, Nicaragua y Costa Rica) y que desde entonces han tenido una historia en común, mediatizada por 
intentos de integración en diferentes momentos, conflictos limítrofes y la lucha contra múltiples intereses expansionistas de las potencias mundiales de turno, debido a una posición geográfica estratégica.

Hasta llegar, a décadas más recientes, a otras clasificaciones que obedecen a lo relacionado con la economía y la política internacional. "Desde la económica y la política Panamá y Belice se encuentran cada vez más vinculados. También se ha acrecentado la idea de que Centroamérica comparte lazos importantes con el sureste mexicano [...] Esta idea tuvo su génesis en el Gobierno mexicano durante el período del presidente Vicente Fox, aunque con antecedentes en el del señor Carlos Salinas de Gortari” (Cuevas Molina, 2012, pp. 18).

Además del espacio cultural mesoamericano, se encuentra el espacio caribeño, casi como un mundo aparte, con su propia historia y manifestaciones culturales, pero con una enorme influencia en las costas centroamericanas. Cita Cuevas a Fábregas Puig, en referencia a los beliceños "[...] que son parte nuestra, de nuestra regionalidad, y no solamente son caribeños y que esa pata en el Caribe y esa pata en Centroamérica que ellos tienen, lejos de ser una desventaja es una enorme ventaja porque ellos nos muestran la conexión que tenemos, aquí en Costa Rica, en Guatemala a través de las culturas garífonas, y que está en Nicaragua también en la Costa Atlántica" (Cuevas Molina, 2012, pp. 75).

Por otra parte, se encuentra la Centroamérica extendida que abarca a los grupos de la región, procedentes de culturas regionales diferentes, lenguas variadas, emigrados a los Estados Unidos que se enfrentan y adoptan otros patrones culturales y de pensamiento, pero que todavía conservan elementos culturales de su territorio de origen.

En este sentido nos enfrentamos al concepto de transculturación. Cita Pulido Tirado al cubano Fernando Ortiz:

Entendemos que el vocablo 'transculturación' expresa mejor las diferentes fases del proceso transitivo de una cultura a otra, porque este no consiste solamente en adquirir una distinta cultura, que es lo que en rigor indica la voz angloamericana "aculturación", sino que el proceso implica también necesariamente la pérdida o desarraigo de una cultura precedente, lo que pudiera decirse una parcial "desculturación", y además, significa la consiguiente creación de nuevos fenómenos culturales que pudieran denominarse "neoculturación" [...] En todo abrazo de culturas sucede lo que en la cúpula genética de los individuos: la criatura siempre tiene algo de ambos progenitores, pero también siempre es distinta de cada uno de los dos. En conjunto, el proceso es una "transculturación", y este vocablo comprende todas las fases de su parábola" (Pulido Tirado, 2010, p. 56).

El término Centroamérica es complejo, tiene muchas aristas por lo que se hace necesario delimitar los puntos de análisis. Es innegable el valor geoestratégico que tiene la región a nivel continental. "Geoestratégica quiere decir que es (y ha sido) estratégica por, para usar dos conceptos comunes en geografía, su sitio y situación. El sitio: un istmo. La situación: área vital de paso en planes de dominio a nivel mundial" (Granados Chaverri, 1985, p. 76). 
En esta perspectiva, no hay ningún motivo para excluir a Panamá o para no incluir a Belice en una definición moderna de Centroamérica. Ello agregaría mayor diversidad a un área ya bastante variada, en términos históricos, políticos, económicos, sociales y culturales. Pero rescataría el hecho básico de que los intereses geopolíticos no han reparado en estas diferencias, y han operado y lo harán en el futuro con una estrategia de conjunto para toda la región. Centroamérica son siete y no cinco países (Granados Chaverri, 1985, p. 59-78).

Esta historia ha definido la idiosincrasia de los países del istmo, su visión de mundo, preocupaciones, costumbres, manifestaciones artísticas. Para efectos de este trabajo el énfasis será desde una perspectiva cultural antropológica. En un espacio cultural y geográfico que incluirá a los siete países de la región con sus diferencias y sus elementos homogenizadores. Por un lado, la dimensión histórica, sus puntos de unión y, por otro lado, el pasado y el presente centroamericano con sus procesos, identidades sociales y retos políticos y económicos.

\section{La enseñanza del español en el siste- ma educativo brasileño}

La enseñanza del español en Brasil se remonta a la década de los años cuarenta del siglo XX cuando se incluye en el currículo de las escuelas secundarias brasileñas.

En 1942, durante la Segunda Guerra Mundial y con el gobierno dictatorial de Getúlio Vargas, la Reforma Capanema sustituyó la obligatoriedad del italiano y del alemán por el español. Era la primera vez que el idioma se incluía en el currículo obligatorio del Ciclo Secundario por medio de la Lei Organica do Secundário \# 4.244/42" (Kawamot y Eres Fernández, 2012, p. 283).

Sin embargo, las investigadoras señalan que adquiere muy poca relevancia y en las décadas de los años 60 y 70 hay poco interés por el estudio del español. En la década de los años 80 cambia y se retoma el interés por el estudio del español, y se vuelve a incorporar en la enseñanza pública. Además, hay un desarrollo en la investigación académica universitaria y en el mercado editorial en la producción de materiales didácticos asociados a la enseñanza del español. La lucha por el regreso del español a la enseñanza regular empieza en los años 80, especialmente después de la fundación, en 1981, de la Asociación de Profesores de Español del Estado de Río de Janeiro (APEERJ). La primera victoria importante de la organización ocurre en 1989, cuando la Constitución de Río de Janeiro determinó la obligatoriedad de la enseñanza del español en el currículo de los centros estaduales de la enseñanza media (Kawamoto y Eres Fernández, 2012, p. 284).

Por otra parte, durante la segunda mitad de la década de 1980, se realizan los primeros Congresos de Profesores de Español en Brasil.

A partir de ahí empiezan a organizarse muchos eventos, tales como los encuentros de Profesores de Español a cargo de diferentes Asociaciones de Profesores de Español o Seminarios de Interferencias Lingüísticas, bajo la responsabilidad de la Consejería de Educación de 
la Embajada de España" (Eres Fernández, 2000, pp. 63-64).

En la década de los noventa se da un boom de la enseñanza del español en Brasil. Esto afecta de manera significativa el mercado editorial y la disponibilidad de materiales. "[...] se manifiesta con la implantación de un gran número de centros de enseñanza que ofrecen cursos de español, a la vez que las escuelas regulares de educación básica empiezan a incluir el castellano entre las asignaturas opcionales $\mathrm{u}$ obligatorias" (Eres Fernández, 2000, p. 65).

A raíz de esa idea generalizada del aprendizaje del español en suelo brasileño, los investigadores, académicos e intelectuales universitarios se han dado a la tarea de potenciar la importancia de la cultura hispana en ese país.

Los últimos diez años han sido benéficos para nuestra cultura en Brasil. Ha crecido el prestigio de algunas cátedras universitarias de español. Lo hispanoamericano, que siempre tuvo, paradójicamente menos vigor que lo español en lo que se refiere a su estudio en las universidades, comienza a preocupar bastante, como es lógico, y crece en estos momentos (García Morejón, 1990, pp. 18-19).

Y agrega que el Brasil ha ido dándose cuenta de la importancia que tienen sus vecinos hispanoamericanos y de lo urgente de una integración económica y cultural iberoamericana. Sin embargo, ya desde la década de los años cuarenta del siglo XX, en la educación superior, se había empezado a enseñar temas relacionados con la cultura hispana en general, con mayor énfasis en la literatura hispanoamericana. Así, en las décadas siguientes, se incorporaron cursos y cátedras en universidades de diferentes estados. Diferentes cursos de literatura hispanoamericana se introdujeron en los programas de licenciatura y, posteriormente, en las maestrías y doctorados relacionados con el estudio del español.

Cabe señalar la importancia de los Cursos de Extensión ofrecidos por las Universidades brasileñas a las comunidades. Son cursos por lo general temáticos y vienen a suprimir la imposibilidad de abarcar todo en las clases o aun actualizar profesores de la enseñanza media o superior. Se dirigen a estudiantes, profesores e interesados en la literatura hispanoamericana. Muchos de ellos son impartidos con la participación de la Consejería de educación de la Embajada de España o del Instituto Cervantes (Guberman, 1990, p. 114).

Sobre la presencia del español hispanoamericano en la Educación Superior Brasileña al principio del siglo XXI había más de 50 universidades (públicas y privadas) que ofrecían como asignaturas optativas la lengua española y las literaturas española e hispanoamericana. También, las licenciaturas en portugués y español estaban presentes en 22 universidades. Además, las universidades más importantes del país, con reconocida labor científica, ofrecían estudios de postgrado en lengua española y literaturas hispánicas. Brasil estaba intentando comprender su papel dentro de la comunidad iberoamericana, formada también por Portugal, España y toda Hispanoamérica (Nascimiento, 1999, p. 188). 
El 5 de agosto de 2005 se promulgó la ley 11.161, la cual hace obligatoria la enseñanza del español en las escuelas de enseñanza media públicas y privadas. Esta provocó algunas transformaciones, por ejemplo, el aumento de plazas para profesores de español en las instituciones superiores, la realización de cursos para profesores y la apertura de seminarios de actualización y educación continuada. Además, la apertura de sedes del Instituto Cervantes $y$, con este, la ampliación de cursos de lengua española, actualización y difusión cultural; ofertas de becas y aumento de publicaciones (Kawamoto y Eres Fernández, 2012, p. 287).

La medida anterior reforzó el interés por el aprendizaje de la lengua española en Brasil y a nivel institucional se comenzaron a hacer esfuerzos en la formación de profesores de español brasileños y en los círculos académicos a ser tema de investigación y discusión en seminarios y congresos. Las culturas hispánicas y lusitanas latinoamericanas han estado por muchos años tan cerca geográficamente, pero tan lejos culturalmente, pues nunca antes había habido un interés tan fuerte de integración, de estudiarse y conocerse mutuamente.

\section{Metodología de Español como Lengua Extranjera (ELE)}

La metodología utilizada en las actividades realizadas con los estudiantes se basó en el Método Comunicativo, el enfoque por tareas y el aprendizaje por medio de la indagación. El método llamado enfoque comunicativo (Communicative Approach) o Enseñanza Comunicativa de la Lengua
(Communicative Language Teaching) ha influido la enseñanza de las lenguas extranjeras desde principios de los años setentas y los años ochenta y está asociado a la lingüística cognitiva.

El enfoque comunicativo abre una perspectiva más amplia de una lengua. En concreto nos hace considerar la lengua no solo en función de sus estructuras (gramática y vocabulario) sino también a partir de las funciones comunicativas que cumple (Littlewood, 1998, p. 10).

Unido al enfoque comunicativo se encuentra el concepto de competencia comunicativa, la cual va más allá de competencia lingüística (fonológico, sintáctico, léxico o semántico) e incorpora también el conocimiento de las reglas de uso de la lengua y también la conexión con el contexto cultural, social e histórico de la lengua que se está aprendiendo.

La competencia comunicativa es el término más general para la capacidad comunicativa de una persona, capacidad que abarca todo el conocimiento de la lengua como la habilidad para utilizarla. La adquisición de tal competencia está mediada por la experiencia social, las necesidades y motivaciones, y la acción, que es a la vez una fuente renovada de motivaciones, necesidades y experiencias (Hymes, 1974, pp. 48-89).

De esta manera, la competencia comunicativa no se puede reducir a la competencia gramatical de una lengua, a la habilidad de manejar las estructuras, sino que hay que saber situarse en el contexto comunicativo de cada comunidad específica, en sus diversas formaciones sociales, culturales e ideológicas. 
Por otra parte, surgido del Enfoque Comunicativo, se encuentra la enseñanza de la Lenguas Extranjeras Mediante Tareas (ELEMT), la que no constituye un método sino una opción dentro del método mencionado. Consiste en la enseñanza por medio de tareas, la utilización de materiales originales elaborados por el docente y la participación activa del estudiante. Todo lo anterior da valor al concepto de competencia comunicativa. Pues lo alumnos desarrollan prácticas lingüísticas comunicativas y actividades de uso lingüístico, que involucran aspectos relacionados con la cultura y el arte. Además, la adopción de la enseñanza mediante tareas conlleva un cambio de la perspectiva de los papeles de los docentes y los alumnos. "Quizá su diferencia fundamental radica en una concepción rica de la lengua y en la forma de planificar y organizar las actividades o tareas que constituyen las clases" (Zanón, 1999, p. 8).

Parte de la materialización de las tareas será mediante el aprendizaje por medio de la indagación, el cual se basa en la idea de adquirir conocimientos, información y destrezas por medio de la investigación, a partir de preguntas y problemas. Se parte de la construcción del conocimiento; no se da construido, es el alumno quien participa activamente en la construcción.

En ese sentido, Gordon Well y Rebeca Mejían citan a Jean Lave y Ettiene Wenger:

Las actividades orientadas a la indagación, en contraste, incrementan la propia comprensión de los temas y procedimientos que resultan importantes porque contribuyen a desarrollar aquello que la persona necesita saber dominar, para poder tomar parte activa y tener una identidad como miembro de una comunidad particular. Idealmente, por consiguiente, el aprendizaje que se da en una comunidad de indagación no es un fin en sí mismo o el objetivo de la actividad, sino un aspecto intrínseco del trabajo en el contexto de actividades que trascienden el currículo prescrito (Wells y Mejía, 2005, p. 4).

\section{Contexto de la investigación}

La investigación se llevó a cabo en el Departamento de Lengua y Literatura Extranjera (DLLE), en el Centro de Comunicación y Expresión (CCE) de la Universidad Federal de Santa Catarina (UFSC) ${ }^{1}$.

Es una universidad pública y gratuita, fundada el 18 de diciembre de 1960. En el momento de la investigación, estaba considerada una de las cinco mejores universidades brasileñas desde el punto de vista de la población y de la calificación de su cuerpo docente. Además, la sexta de América Latina y la 205 del mundo según el Webometrics Ranking of World Universities de 2013. Es una institución que se dedica a actividades de enseñanza, investigación y extensión, lo que contribuye con el desarrollo cultural, económico y social de Santa Catarina y Brasil. Para el 2014, tenía más de 35.000 estudiantes matriculados en cursos de posgrado, grado, educación a distancia, enseñanza técnica, media, fundamental e infantil.

En 2009, la Universidad expandió su oferta de enseñanza por medio de tres campus en las ciudades caterinenses de Aranguá, Curitibanos y Joinville y, en 2013, en Blumenau. También, se ha internacionalizado por medio de 
cooperación con instituciones de enseñanza en todo el mundo. Tiene más de 300 convenios activos con 38 países.

El trabajo de investigación fue llevado a cabo en el campus Reitor João David Ferreira Lima, localizado en el barrio Trindade en la ciudad de Florianópolis, en el Centro de Comunicación y Expresión (CCE). Actualmente, posee cinco departamentos: Expresión Gráfica (EGR), Periodismo (JOR), Lenguas y Literaturas Extranjeras (DLLE), Lengua y Literatura Vernáculas (LLV) y el Departamento de Artes Liberales (DALi).

El plan de estudios cuenta con 8 fases (semestres), es decir, cuatro años e incluye cursos en el área de Lingüística y Literatura. Por ejemplo, en la primera área, se ofrecen cursos de Lengua Española, Lingüística Aplicada, Estudios del Lenguaje y de Traducción. En el área de Literatura se dan cuatro cursos de Literatura Hispánica. En la fase 8 , la oferta de cursos relacionados con la literatura se amplía. Hay un abanico de cursos optativos. Se pueden escoger cursos como Literatura y Cinema, Literatura Infantil y Juvenil, así como, Tópicos de Literatura Hispánica, enfocados en poesía o teatro, entre otros.

El Departamento de Lengua y Literatura Extranjera (DLLE) cuenta con recursos tecnológicos. Cada aula está acondicionada con equipo de sonido, televisión, DVD, vídeo y computador con DataShow. Además, dispone de un laboratorio de Lenguas Extranjeras, donde se realizan prácticas destinadas al mejoramiento de la pronunciación y la comprensión auditiva. Igualmente, existe un laboratorio de informática a disposición de los estudiantes para investigación en internet o la preparación de trabajos académicos. $Y$ hay dos auditorios equipados para la realización de conferencias, proyección de películas, defensa de trabajos de graduación o demás actividades.

Estas ventajas de planta física y tecnológica facilitaron el desarrollo de las actividades y talleres con los estudiantes. Sin embargo, hubo otras dificultades relacionadas con la asistencia total y regular de los alumnos a todas las sesiones de clase, ya que en el momento de la investigación comenzó una huelga de trabajadores de la Universidad Federal de Santa Catarina (UFSC). No detuvo las lecciones, pero dificultó servicios destinados a los estudiantes y a los profesores, como el comedor escolar y el servicio de biblioteca, tanto el préstamo de libros como su consulta y el uso de sus instalaciones para realizar tareas y demás trabajos de investigación.

Con respecto a los informantes, estos se dividían en dos grupos: los profesores y los estudiantes. Las cuatro profesoras con las que trabajé eran de nacionalidad brasileña, tenían entre 30 y 37 años, dos de ellas doctoras en Lengua Española y dos ostentaban la maestría en el área. Su carga es de 12 horas semanales en el trabajo de aula y el resto del tiempo lo destinan a la investigación y el planeamiento de clases.

El cuerpo docente del área de español está formado por 12 profesores, la mayoría lusoparlantes, aunque también hay dos profesores suramericanos y una española. Con respecto a las instalaciones, cada dos profesores comparten una oficina, la cual está equipada con dos computadoras, una mesa de reuniones y una biblioteca personal. Además, cuentan con el apoyo de un estudiante asistente. Por otra parte, para el uso de las herramientas tecnológicas en las clases hay un equipo de soporte técnico que se encargaba de la instalación y supervisión. 
La metodología en las clases de lengua es magistral y participativa. Les corresponde a los estudiantes hacer pequeñas investigaciones y presentaciones orales. Las lecturas de clase, tareas y asignaciones se encontraban cargadas en la página virtual del departamento. El número de estudiantes por clase variaba entre 20 y 25 estudiantes según el nivel.

El grupo mayoritario de informantes, los estudiantes, tiene un rango de edades que va desde los 18 años, jóvenes que acaban de terminar los estudios secundarios, hasta adultos mayores que llegan a 60 años. Algunos son estudiantes de tiempo completo, y otros tienen trabajos de medio tiempo. En su mayoría son del estado de Santa Catarina, pero también provienen de otros estados de niveles socioeconómicos variados: bajo, medio y alto.

Sus motivaciones para estudiar español son variadas; algunos lo hacen buscando mejores oportunidades laborales, por gusto hacia la lengua y cultura hispana, y otros simplemente porque no fueron aceptados en las carreras de preferencia y, por eso, deciden estudiar una lengua extranjera por un tiempo limitado hasta que puedan ingresar a estudiar lo deseado.

El nivel de los estudiantes en cuanto a destreza de las habilidades oral, auditiva, escrita y lectora es muy variado en todos los niveles de la carrera de la Licenciatura en Letras-Español. Algunos estudiantes previamente a empezar a cursar la carrera ya han tenido estudios de la lengua española, la han estudiado en la escuela secundaria o en alguna escuela particular o porque han vivido en algún país de habla hispana, entre algunas razones. Por el contrario, la mayoría de los estudiantes nunca ha tenido una aproximación tan fuerte con la lengua hasta que no empiezan la carrera en la universidad.

En los diferentes niveles de la licenciatura, es posible encontrar estudiantes que son hablantes nativos del español. Tienen diferentes orígenes, en su mayoría son de países fronterizos. Desean certificarse para enseñar español formalmente. En algunos casos, son residentes en el país o son brasileños de padres hispanohablantes.

Si nos atenemos a la medición establecida por el Marco Común Europeo de Referencia para las lenguas (MCER) ${ }^{2}$, en cualquiera de las ocho fases del plan de estudios de la licenciatura en Letras-Español, es posible que haya estudiantes de todos los niveles: desde el nivel A (usuario básico), pasando por el B (usuario independiente), hasta llegar al nivel C (usuario competente), además de los hablantes nativos.

La anterior situación no deja de ser un obstáculo para el desarrollo fluido de las lecciones. Dificulta el trabajo del docente y perjudica el aprendizaje del alumno, pues dependiendo del tema en estudio, las actividades pueden resultar poco retadoras o, por el contrario, con un grado de dificultad muy alto. Sin embargo, no existe la posibilidad de separar en el primer año a los estudiantes en los niveles estipulados por el MCER, pues significaría una inversión económica altísima, y un caos administrativo de organización de programas. Para compensar un poco la situación, en los primeros niveles, los estudiantes tienen la ventaja de contar con un tutor hablante nativo del español, quien puede ayudarlos con las tareas y con aspectos de gramática y pronunciación desarrollados en los diferentes cursos. Es una oportunidad 
que ofrece el departamento y es decisión de cada estudiante aprovechar el recurso humano ofrecido.

La mezcla de niveles lingüísticos de los estudiantes en las diferentes fases de la carrera de español es una queja constante, desde cualquier posición en que se encuentren los estudiantes, ya sean hispanohablantes o lusoparlantes. Estos últimos, se sienten en una franca desventaja con respecto a sus compañeros de curso que hablan español como lengua materna, pues argumentan que elevan el nivel de las clases a un punto muy alto, al que ellos se aproximarán una vez concluido su plan de estudios de cuatro años. Por el contrario, los estudiantes hispanohablantes alegan que un estudiante que está haciendo un programa de este tipo, enfocado en literatura y lingüística, debería entrar con un nivel de español más alto.

\section{Los participantes}

En la primera semana se realizó un conversatorio con las profesoras Dra. Oliveira, quien enseña Lengua Española III; Msc. Parrini, que imparte el curso Lengua Española VIII; y Msc. Teixeira del curso Lengua Espanola I. Se abordaron los siguientes aspectos: didácticos, en cuanto a la metodología utilizada en las clases y los materiales de apoyo y aspectos de lengua. En este punto, destaca el interés por el español en la ciudad de Florianópolis y la situación laboral en el sistema de educación primaria y secundaria, público y privado como campos laborales para los futuros profesores de español. Además, se abordó el tema de Centroamérica, con respecto a temas de la cultura en general y arte.

\section{Aspectos del interés por el español}

La ciudad de Florianópolis recibe cada año un enorme flujo de turistas provenientes de Uruguay, Argentina y Chile. A pesar de esta situación, y de la ley del español o Ley 11161 del 7 de julio de 2005, la cual obliga a todos los centros de educación primaria y secundaria a incluir la enseñanza de español en su plan de estudios, todavía hay poco interés por aprender y hablar la lengua, en opinión de las profesoras. Señala la Dra. Oliveira "hay más interés en hablar inglés, en primer lugar, y otras lenguas como alemán, italiano y francés".

Por otra parte, con respecto a las posibilidades laborales de los futuros profesores de español que se están formando, la profesora Parrini explica que no hay muchas oportunidades para trabajar como profesores de primaria o secundaria, pues aunque existe una ley, esta se ha quedado en el papel, ya que no todos los centros de enseñanza la siguen.

Además, señala que los trabajos que se ofrecen son temporales, no hay estabilidad y los salarios son muy bajos. A la vez, en las escuelas de lenguas en el sector privado, continúa siendo el español la lengua menos estudiada. La remuneración obtenida por impartir clases privadas es muy baja. Lo anterior hace que la mayoría de los estudiantes de cada generación, en algún momento de la carrera, opte por no continuar la Licenciatura en LetrasEspañol y buscar otra alternativa que le permita usar la lengua en otros ámbitos, pero no como profesores. 


\section{Aspectos relacionados con Centroamérica}

Con respecto a la región de Centroamérica, las profesoras aceptaron no conocer casi nada en relación con aspectos de cultura general, el arte o a las variedades lingüísticas de la región. A excepción de la Dra. Oliveira, quien conocía la biografía de la guatemalteca Rigoberta Menchú y había leído partes del testimonio Me llamo Rigoberta Menchú, así me nació la conciencia. Por tal razón, Menchú es un personaje centroamericano que siempre está presente en sus clases cuando tiene que hacer referencia a aspectos culturales de nuestros países.

Como profesoras de los cursos del área de Lingüística, se enfocan en algunos países suramericanos y hacen referencia a aspectos culturales generales de México y Cuba que son los países lejanos de América Latina más conocidos por los brasileños. En vista de esta situación, las docentes mostraron interés en contar con material y datos relacionados con la región centroamericana, partiendo del hecho de que casi todos los estudiantes de los diferentes niveles de la carrera de la Licenciatura en Letras-Español no tenían ningún conocimiento sobre esta región; por lo tanto, cualquier información sería interesante y novedosa.

\section{Proceso de investigación}

La observación participante fue fundamental durante el desarrollo de la investigación. Permitió sacar conclusiones generales a partir de experiencias particulares. El microcosmos del salón de clase fue donde se concentraron por más tiempo los dos grandes actores del proceso: estudiantes y docentes.
La asistencia y observación de clases tenía como objetivo conocer a los estudiantes desde una perspectiva más cercana, tanto en el nivel académico como personal, lo mismo que los profesores. Además, recabar información sobre los temas incluidos en los programas de los diferentes cursos, los materiales y la metodología didáctica utilizada por las docentes. Igualmente, otro de los objetivos consistía en observar las referencias culturales y artísticas hacia los diferentes países hispanoamericanos, con especial acento en la región centroamericana.

Las clases observadas correspondieron a los cursos de Lengua Española I, III y VII, los cuales incluían muchos temas relacionados con la lingüística aplicada, la gramática y, en el caso de Lengua VII, la literatura también. Las referencias a aspectos culturales de la cultura hispanoamericana durante las clases están definidas por las experiencias lingüísticas de la docente, es decir, si su formación práctica de la lengua fue en Argentina, sobre ese país será la mayoría de los aportes. Asimismo, tiene peso la variante dialectal que aprendieron durante su formación académica en la universidad, que en la mayoría de los caso es la de España.

Con respecto a la región centroamericana, las referencias son mínimas, pues es un lugar poco conocido también para las docentes. En la clase de Lengua Española III, un tema estudiado fue el de las variedades lingüísticas de América Latina, y durante el desglose de las regiones, se mencionó a Centroamérica, la cual es vista como un todo, pues se desconoce cuáles son los países que la conforman. Este punto fue una constante en la mayoría del alumnado.

En síntesis, con respecto a las observaciones de las clases, estas se resumen en los siguientes puntos: 
1. Hay en promedio de veinte estudiantes por grupo; la mayoría son mujeres.

2. Existe presencia de estudiantes cuya lengua nativa es español.

3. La mayoría de los estudiantes lusoparlantes no piensan seguir la enseñanza del español. Prefieren usar la lengua en el campo de la traducción, corrección de textos $\mathrm{u}$ otros espacios laborales; no así los hablantes nativos, cuyo objetivo, fundamental al ingresar en la carrera, fue obtener un certificado que les permita enseñar la lengua en un sistema de educación formal.

4. Algunos estudiantes están allí de manera transitoria, mientras pueden entrar a la carrera deseada; la parte de aprender español la ven como un plus para su futuro profesional.

5. La metodología utilizada por las docentes es una combinación, magistral y de participación por parte del estudiante, mediante intervenciones, pequeñas presentaciones e investigaciones.

6. Las aulas cuentan con recursos tecnológicos para el desarrollo de las lecciones.

7. Los materiales utilizados por los profesores son, en su mayoría, de origen español o suramericano, con preferencia de textos y películas argentinas.

8. La relación entre las docentes y los estudiantes es cercana y personal.

9. Cada curso se imparte cuatro veces por semana; cada sesión de clase tiene una duración de 2 horas y 50 minutos.

10. El conocimiento de la región centroamericana por parte de los estudiantes y las docentes es casi nulo.

Mediante conversaciones informales, entrevistas formales, revisión de libros de texto, cuestionarios y encuestas se obtuvieron los datos. Se observó el punto de vista, los intereses, motivaciones para el aprendizaje del español, el grado de conocimiento e interés por la cultura centroamericana, además de determinar las metodologías utilizadas y preferidas, los libros de textos y otros recursos didácticos de los que disponen. Se aplicaron los siguientes instrumentos de recolección de información.

Entrevista formal. Se realizaron entrevistas semiestructuradas, mediante preguntas abiertas, al inicio a manera de exploración o diagnóstico y, durante el desarrollo de la investigación, como una forma de dar seguimiento y describir la evolución del proceso investigativo.

Encuesta. Se aplicaron dos encuestas descriptivas, una dirigida a los profesores que enseñan la carrera de español y la otra a los estudiantes de la carrera. El objetivo fue descubrir en qué situación se encuentra el programa de estudios con respecto a los contenidos sobre la cultura centroamericana. Para la recolección de los datos se utilizó un cuestionario.

Cuestionario. Para registrar y estandarizar la información solicitada a los informantes, profesores y estudiantes se hizo uso del cuestionario. Estaba compuesto por preguntas cerradas con el fin de asegurar la uniformidad a la hora de cuantificar los resultados y a la vez asegurar la objetividad.

Registro anecdótico o diario del investigador. Se utilizó el registro anecdótico como instrumento descriptivo de episodios, situaciones, observaciones o anécdotas significativas, las cuales es- 
taban vinculadas al tema de estudio. Se utilizó para la documentación y descripción del contexto físico, académico y pedagógico, para las observaciones de clases, las conversaciones informales con docentes y estudiantes.

De acuerdo con la aplicación de los instrumentos anteriores y sus resultados, se planearon y diseñaron los talleres didácticos. Se atendieron sugerencias de las profesoras y deseos de los estudiantes. Por medio de obras literarias, musicales y cinematográficas, se abordaron nudos temáticos, se trató de que los alumnos descubrieran la región centroamericana.

Los talleres didácticos. La estructura de los talleres estaba conformada por los siguientes elementos: tema, descripción, objetivos y actividades, y se desarrollaron en un tiempo estipulado, distribuido en horas en diferentes secciones. Los talleres realizados fueron los siguientes: 1. Centroamérica, puente geográfico y cultural; 2. Variedades lingüísticas hispanoamericanas: frases idiomáticas $\mathrm{y}$ usos pronominales; 3 . El testimonio centroamericano en el contexto de la Guerra Fría; 4. Hilos conductores en la temática de diferentes géneros artísticos; $\mathrm{y}$ 5 . Lectura, interpretación y representación teatral de textos poéticos.

Estos abordaron las dos grandes áreas del plan de estudios de la carrera de Licenciatura en Letras-Español: lingüística y literatura. En el primer caso, se realizó un taller de variables lingüísticas de América Latina con especial énfasis en los países de Centroamérica. Interesaba que los estudiantes pudieran escuchar e identificar diferencias fonéticas (corpus de canciones de diferentes países de América Latina) y que aprendieran para un concepto vocablos de diferentes países, además de expresiones idiomáticas características de cada uno. Finalmente, que conocieran que el fenómeno pronominal del voseo no es exclusivo de la región del Río de la Plata.

En el campo literario, se trabajó el testimonio en la modalidad de novela, género muy desarrollado en el contexto de la Guerra Fría, durante las dictaduras y revoluciones ocurridas en la región. Este tema tuvo como objetivo informar al estudiante sobre la historia reciente de la región y sentar una base que explique y aclare las consecuencias de este pasaje en la realidad y época actual.

Por otra parte, se leyeron textos poéticos, literarios y musicales que hacían referencia a temas de la realidad actual centroamericana ${ }^{3}$; por ejemplo, género, literatura gay, migración, medio ambiente, problemas que enfrentan los grupos indígenas y temáticas universales como: amor, relaciones de pareja, conceptos de familias, felicidad, costumbres, entre otros. Estos textos se trabajaron en la parte que corresponde a las actividades de los talleres. Se siguió el método comunicativo, el enfoque por tareas y el aprendizaje por medio de la indagación.

\section{Análisis de los datos}

El enfoque predominante en el proyecto fue el cualitativo; sin embargo, se incorporó la técnica del cuestionario con el objetivo de hacer una medición numérica a partir de la estadística, con el fin de establecer datos relevantes por sexo, año de carrera, dominio de otras lenguas extranjeras, las principales motivaciones por las que estudió la carrera y, sobre todo, definir con exactitud patrones de preferencia en cuanto a la temática desarrollada en los programas de los 
cursos de la población estudiantil que estudia la carrera de español.

A continuación, se hará un análisis estadístico de las variables an- teriores aplicadas a los estudiantes, el cual permitió interpretar los datos que contribuyeron al diseño de la propuesta final.

\section{Tabla 1}

\section{Características generales de la muestra}

Hombres Mujeres Total

Número

$\begin{array}{lccc}\text { Absoluto } & 9 & 41 & 50 \\ \text { Relativo } & 18 \% & 82 \% & 100 \% \\ \text { dad promedio } & 27,67 & 27,71 & 27,70 \\ & 1,67 & 2.20 & 2.10\end{array}$

Como puede apreciarse en la tabla 1., la mayoría de los encuestados fueron mujeres, en una proporción de más de 4 a 1 . Esto debe de tomarse en cuenta para considerar la inconveniencia de realizar análisis desagregados por sexo. La edad promedio es similar para hombres y mujeres, alrededor de 27.7 años, mientras que las mujeres encuestadas en promedio se encuentran ligeramente más avanzadas en sus estudios que los hombres.

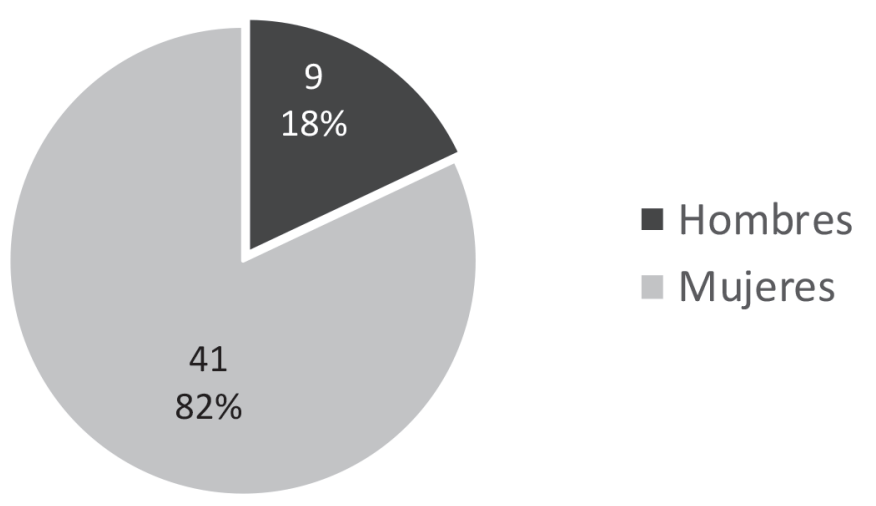

Gráfico 1. Composición de la muestra por sexo. 
En el gráfico 2, se ilustra cómo la mayoría de los encuestados se ubican en su primer año de estudios: 27 de los 50. Le siguen en importancia el tercer y cuarto años. Nótese cómo solo hay 2 estudiantes de quinto año y solo 4 de segundo. En este punto, la muestra se complica, pues no siempre hay congruencia entre la fase en se encuentra y el año de carrera que está cursando el estudiante. El plan de estudios de la carrera Licenciatura en Letras-Español se completa en cuatro años (es decir 8 fases o semestres) si se lleva a cabo de manera constante e ininterrumpida. De hecho, cuando los estudiantes tenían que marcar esta pregunta se mostraron desorientados, pues se presentó una confusión entre los años de carrera y los años reales en que han estado en la universidad. Por ejemplo, se encuentran estudiantes que están en el tercer año de carrera, pero llevan cursos de la tercera fase (que corresponde al segundo año), porque han quedado rezagados por distintas razones: laborales, familiares o porque están repitiendo. También, hay casos de estudiantes hablantes nativos de español que se encuentran en el primer año de carrera, pero que están tomando cursos de la tercera y quinta fases porque se les reconocieron muchos de los cursos de la primera y segunda fases. Así, si la pregunta se hubiera formulado sobre fases o semestres, presentaría las mismas dificultades.

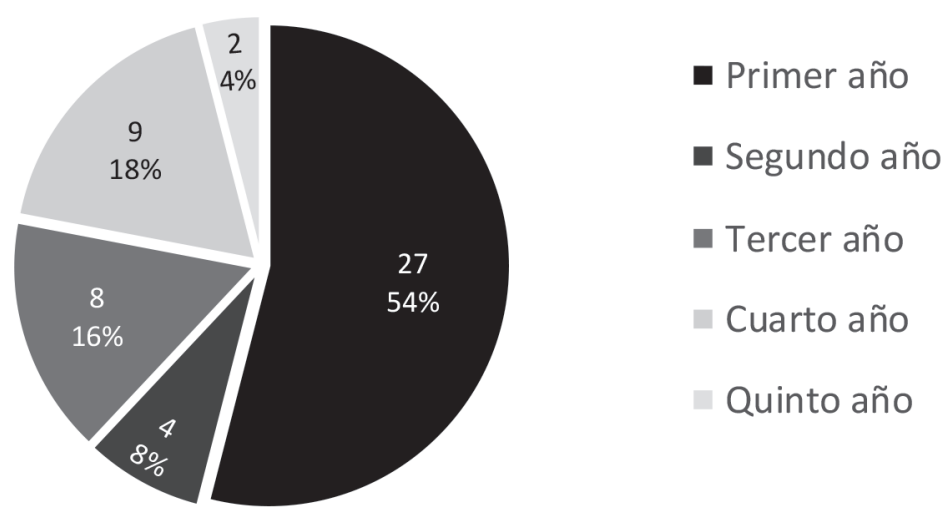

Gráfico 2. Composición de la muestra por año de carrera.

En cuanto al conocimiento de otras lenguas, además de español, poco más de la mitad de los estudiantes encuestados no habla otra lengua aparte de portugués. Del $46 \%$ que sí lo hace, la mayoría habla solamente un idioma adicional y todos ellos hablan al menos inglés. Los otros dos idiomas que se mencionaron fueron francés y alemán (2 menciones cada una). 


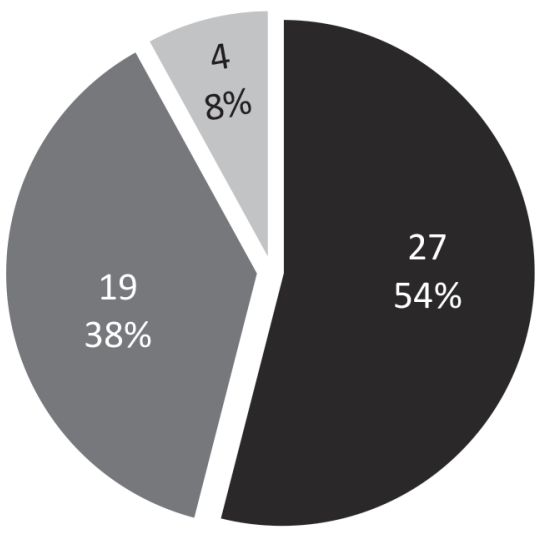

- No habla otra lengua

- Habla solo una más

Habla dos o más

Gráfico 3. Dominio de lenguas extranjeras.

La mayoría de los estudiantes entrevistados preferirían estudiar español en un país suramericano. Sin embargo, se formuló la pregunta sobre la preferencia de una región lejana para estudiar español y las opciones fueron: España, Centroamérica y México. La gran mayoría de estudiantes (72\%) preferiría estudiar español en España,

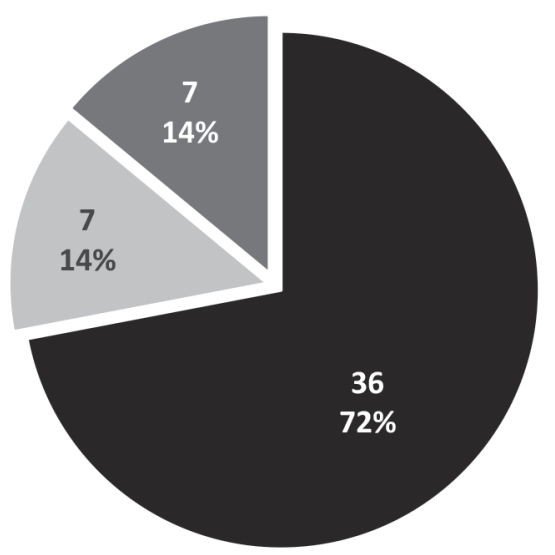

con México y Centroamérica empatando en preferencias. A pesar de que México es un país más conocido y presente en las clases y programas, pudo haber influido la información reciente a través de conversaciones y talleres, lo que motivó la curiosidad de algunos estudiantes por la región hasta ese momento desconocida.

Gráfico 4. Lugares preferidos para estudiar español. 
El gráfico 5 muestra la frecuencia de mención de las razones para estudiar español. Puede apreciarse que las razones más mencionadas, por más de $60 \%$ de los estudiantes, son la 4 "porque me interesan los aspectos culturales" y la 1 "para viajar por países de habla hispana"; en ambos casos, fueros mencionadas principalmente por estudiantes que no dominan otro idioma aparte del portugués. La razón 3 "porque es una lengua bonita" fue mencionada por más de $50 \%$ de los estudiantes, principalmente por estudiantes no políglotas en razón de 2 a 1. La razón menos citada para estudiar otro idioma fue la 7 "para trabajar en un país de habla hispana", solo mencionada por cerca de un quinto de los entrevistados.

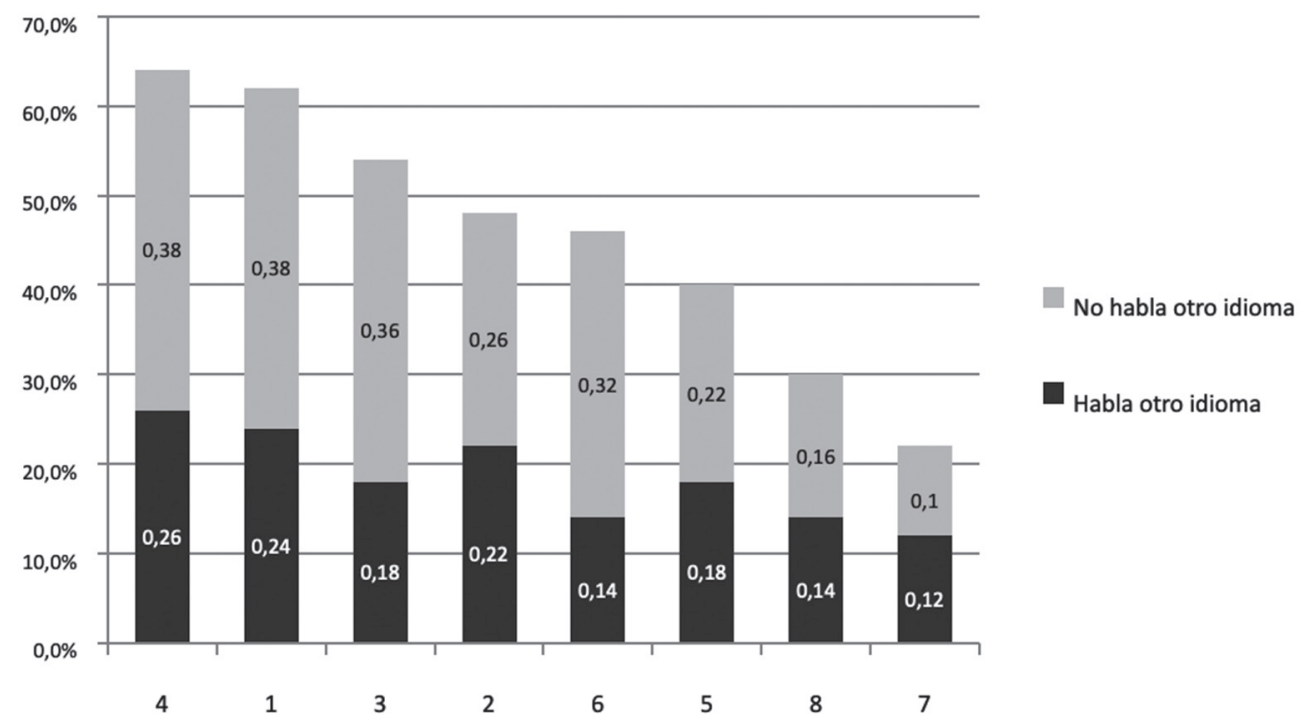

Gráfico 5. Razones para estudiar español Frecuencia de mención, según dominio de idioma extranjero.

Para analizar la frecuencia de mención de las razones para estudiar español de acuerdo con el año de carrera, se aprecia que excluye a estudiantes de segundo y quinto años por ser muy pocos (6 en total). El gráfico 6 permite inferir que las razones 4,1 y 3 son particularmente importantes para alumnos de primer año, mientras que su importancia decrece entre estudiantes de cuarto año. Es aparente que para los más avanzados, las razones 5 "porque me interesa el arte hispano" y 8 "porque tengo familiares y amigos de habla hispana" cobran más importancia que para estudiantes de primer año. Dada la disparidad presente en la muestra entre el número de personas de primer año y del resto de años, estos resultados deben tomarse con cautela, pues podrían ser indicativos de un cambio significativo en los intereses de los estudiantes conforme avanzan en la carrera, gracias a la información adquirida en los diferentes cursos de lingüística y literatura, esto con respecto a la razón 5. Por otra parte, en los años más avanzados de la carrera, es posible ya hayan hecho algunos intercambios $u$ 
otras actividades académicas en países de habla hispana suramericanos. En este contexto, ya han establecido más relaciones y conexiones con personas del mundo hispano. Además, en los cursos más avanzados, había una gran presencia de estudiantes hablantes nativos del español. Estas podrían ser algunas razones que justifiquen la variable 8 para los estudiantes más avanzados en la carrera. En oposición, los estudiantes del primer año no tienen suficiente información y valoraron dos opciones 1 y 4 que son justamente necesarias para acercarse y entender la cultura hispana. La razón 3 es poco razonada y es más el producto de una sensación o sentimiento.

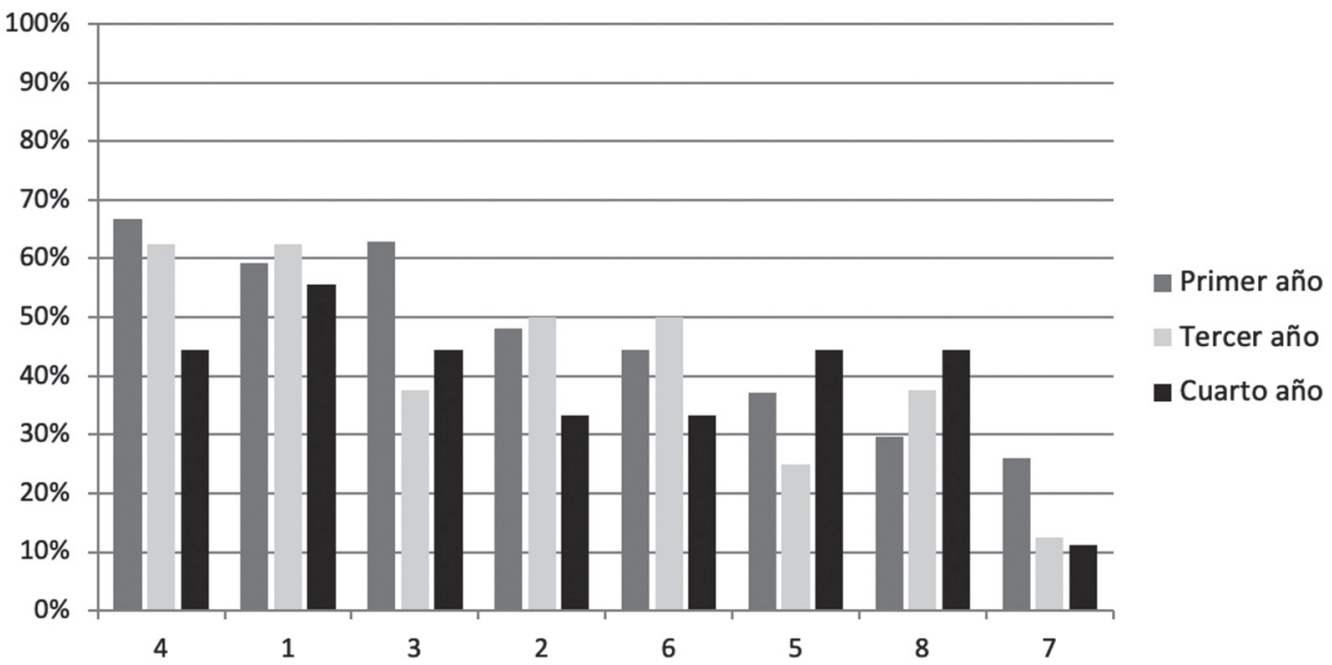

Gráfico 6. Razones para estudiar español. Frecuencia de mención, según año de carrera.

Del análisis de las respuestas sobre aspectos culturales de interés para los entrevistados, destaca que el aspecto más frecuentemente citado es el 7 "costumbres", con un $80 \%$ de menciones. También destaca la escasa importancia de los aspectos 9 "roles de género" y 10 "religiones" entre los entrevistados. Otros comparativamente menos populares son el 4 "aspectos políticos y económicos" y el 8 "geografía". Los restantes aspectos culturales son mencionados por lo menos por $60 \%$ de los entrevistados, mostrando así su relevancia para ser incluidos en los materiales y contenidos del curso optativo de cultura, literatura y cine centroamericanos diseñado para atender a una población constituida por estudiantes de la carrera de la Licenciatura en Letras-Español del Departamento de Literatura y Lengua Extranjera de la Universidad Federal de Santa Catarina. Es importante señalar la relativa mayor importancia que los estudiantes no políglotas otorgan al aspecto 12 "lugares turísticos" y 8 "geografía". 


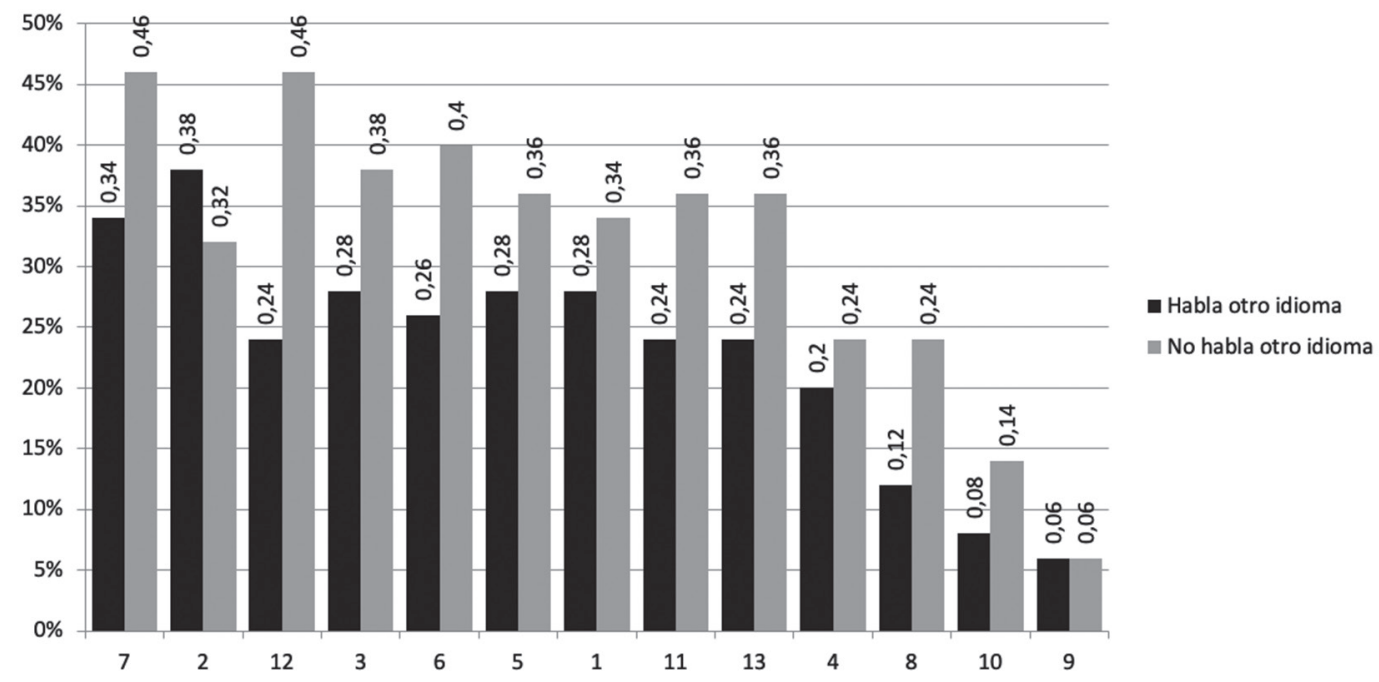

Gráfico 7. Aspectos culturales de interés al estudiar lengua extranjera. Frecuencia de mención, según dominio de lenguas.

Llama la atención que, aunque un $82 \%$ de la población son mujeres, la razón 9 "roles de género" fuera una de las de menor importancia. Tal vez lo escueto de la descripción de la razón 9 pudo generar confusión en los estudiantes a la hora de marcarla. Sin embargo, la razón 10 "religiones" y la 4 "aspectos económicos y políticos" fueron de una menor preferencia por parte de los encuestados. Podría inferirse que la mayoría de la población no está tan interesada en temas que generen polémica y que llevan a la discusión por la diferencia de posiciones. Esto fue más o menos notorio en las clases; eran pocos los estudiantes interesados en dar opiniones sobre temas controversiales, quizás porque las clases no están enfocadas en esa dirección, puesto que parece que las profesoras están más centradas en la descripción de los temas más que en generar crítica en los estudiantes. Por otra parte, resulta interesante que la razón 8 "geografía" sea una de las de menor importancia, solo retomada un poco por los alumnos no políglotas, lo cual es curioso, pues la gran mayoría de los estudiantes no tiene noción de la ubicación geográfica de la mayoría de los países hispanoamericanos, excepto de los que son fronterizos con Brasil.

Por otra parte, también se aplicó un cuestionario a las cuatro profesoras que participaron en el proceso, cuyos resultados no se explicarán de manera estadística y cuantitativa, sino más bien descriptiva. Y se repitieron tres preguntas que los estudiantes respondieron también. Son las siguientes: Cuando enseña español, ¿sobre cuáles aspectos culturales se interesan más sus estudiantes? ¿Cuáles son las tres principales razones por las que sus estudiantes decidieron estudiar la carrera de español? ¿Cuál de los siguientes destinos le recomendaría a uno de sus estudiantes para realizar un programa de inmersión de español? A continuación, se presentan dos cuadros que incluyen los rubros tal y como fueron planteados a las docentes. 


\section{Cuadro 1}

Razones culturales de interés cuando enseña una lengua

\begin{tabular}{lrcrc}
\hline Rubros & Teixeira & Parrini & Oliveira & Hernando \\
& Saldanha & Ferreira & \\
\hline
\end{tabular}

1. Gastronomía

2. Artes en general

3. Aspectos históricos y antropológicos

4. Aspectos políticos y económicos

5. Vida cotidiana de la gente

6. Tradiciones y celebraciones

7. Costumbres

8. Geografía

9. Roles de género

10. Religiones

11. Diversiones y entretenimiento

12. Lugares turísticos

13. Modismos y frases idiomáticas de los diferentes países
En el caso de los estudiantes el rubro más votado, en un $80 \%$, fue el 7 que corresponde a "Costumbres", donde hay una coincidencia con los puntos elegidos por las profesoras, pues tres de ellas lo eligieron también; así también, tres de las profesoras apoyaron los rubros 2 "artes en general", 6 "tradiciones y celebraciones", 11 "diversiones y entretenimiento" y 12 "lugares turísticos". Es importante señalar que los últimos tres rubros fueron escogidos por las profesoras que imparten los cursos de lingüística aplicada. Por otra parte, la profesora que imparte los cursos de literatura se inclinó por los rubros 4 "aspectos políticos y económicos" y 9 "roles de género" que fueron los menos votados por los estudiantes. Las cuatro profesoras coincidieron en el rubro 5 "vida cotidiana de la gente". 


\section{Cuadro 2}

Tres razones por las que sus estudiantes deciden estudiar la carrera de español ${ }^{4}$

\begin{tabular}{lcccc}
\hline Rubros & $\begin{array}{c}\text { Teixeira } \\
\text { Saldanha }\end{array}$ & $\begin{array}{c}\text { Parrini } \\
\text { Ferreira }\end{array}$ & Oliveira Hernando \\
& & \\
\hline
\end{tabular}

1. Para viajar por países de habla hispana

2. Para tener mejores oportunidades laborales

3. Porque es una lengua bonita al oído X $\mathrm{X}$

4. Porque les interesan los aspectos culturales

$\mathrm{X}$ X

5. Porque les interesa el arte hispano $\mathrm{X}$

6. Porque es una lengua muy hablada en el mundo

7. Para trabajar en un país de habla hispana

8. Porque tienen familiares y amigos de habla hispana

9. Porque no lograron entrar a otra carrera

X

$\mathrm{X}$

10. Porque no sabían qué estudiar

X

Sobre las principales motivaciones de los estudiantes para seguir la carrera de lengua española, en un $60 \%$ de los casos, votaron por el rubro 4 "porque me interesan los aspectos culturales, y por el 1 "para viajar por países de habla hispana". En el caso de las profesoras, en esta pregunta, no hubo tantas coincidencias entre ellas y con respecto a los estudiantes. Así, solamente dos de las profesoras coincidieron en el rubro 4 y ninguna marcó el rubro 1.
Hay un punto interesante, en el caso de la opinión de los estudiantes: un $50 \%$ de los no políglotas marcó el rubro 3 "porque es una lengua bonita al oído"; así también, las dos profesoras no políglotas, se inclinaron a pensar en este punto. Por el contrario, las dos profesoras que hablan tres o más lenguas compartieron opinión en el rubro 2 "para tener mejores oportunidades laborales". Y, finalmente, una profesora políglota y una no políglota 
coinciden en el rubro 9 "porque no lograron entrar a otra carrera". Cabe destacar que en el cuestionario para los estudiantes, el rubro 9 antes

\section{Cuadro 3}

\section{Datos generales de las profesoras entrevistadas}

\begin{tabular}{|c|c|c|c|c|}
\hline Rubros & $\begin{array}{l}\text { Teixeira } \\
\text { Saldanha }\end{array}$ & $\begin{array}{l}\text { Parrini } \\
\text { Ferreira }\end{array}$ & Oliveira & Hernando \\
\hline 1. Edad & 36 años & 31 años & 37 años & 37 años \\
\hline 2. Titulación & Máster & Máster & Doctora & Doctora \\
\hline 3. Años de experiencia laboral en general & 7 años & 8 años & 4 años & 7 años \\
\hline $\begin{array}{l}\text { 4. Años de experiencia en Educación } \\
\text { Superior. }\end{array}$ & 3 años & 3 años & 3 años & 4 años \\
\hline $\begin{array}{l}\text { 5. Lenguas habladas, además de español } \\
\text { y portugués. }\end{array}$ & ninguna & ninguna & inglés & $\begin{array}{l}\text { catalán, } \\
\text { inglés, francés }\end{array}$ \\
\hline $\begin{array}{l}\text { 6. Destino que recomendaría para un } \\
\text { programa de inmersión en español. }\end{array}$ & $\begin{array}{c}\text { España } \\
\text { Centroa- } \\
\text { mérica } \\
\text { México }\end{array}$ & $\begin{array}{l}\text { Centroa- } \\
\text { mérica }\end{array}$ & México & México \\
\hline
\end{tabular}

Con respecto a la pregunta “ ¿Cuál de los siguientes destinos le recomendaría a uno de sus estudiantes para realizar un programa de inmersión de español?", existían tres opciones a escoger: España, Centroamérica y México, de la misma manera que el cuestionario dirigido a los estudiantes, con la diferencia que, por medio de una pregunta abierta, las docentes debían explicar las razones que justificaban su escogencia. En el caso de las profesoras Oliveira y Hernando, se inclinaron por México. La primera lo justifica diciendo lo siguiente: "Como conozco poco aspectos mencionado y el 10 "porque no sabían qué estudiar" no estaban presentes como opción por marcar.

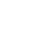


ni conocemos a músicos, no sabemos mucho sobre estos países, así que sería una excelente oportunidad conocer a fondo una cultura que, en la universidad, no se trata mucho. Ellos tienen profesores y colegas españoles, argentinos, peruanos, chilenos... pero, en general, no tienen contacto con centroamericanos. Además, me imagino que la cuestión financiera también sería un factor relevante: ir a España, probablemente, nos saldría mucho más caro que ir a Centroamérica, cuyas monedas no deben costarnos tanto como el euro. Además, el clima, la comida y la gente, me imagino, le favorecerían como para estar unos meses en un país extranjero. Creo que en Centroamérica un brasileño estaría más cómodo que en España, si se piensa en una estadía de meses".

En el caso de la profesora Saldanha, no le fue posible escoger una sola opción y así lo expresó: "Recomendaría todos pues creo que toda experiencia que uno pueda tener en otro país sería de gran importancia para su aprendizaje académico, profesional y personal. Cada lugar tiene sus riquezas y son igualmente especiales".

\section{Centroamérica la región desconocida}

En las entrevistas abiertas realizadas a los estudiantes, se comprobó que hay un desconocimiento casi total de la región centroamericana, espacio geográfico donde se encuentran países que lo conforman, grupos étnicos y lenguas existentes. Una estudiante de Español Lengua I comentó: "Sobre Centroamérica, creo que está muy débil, porque no sabemos mucho y siempre que leemos algo es de personas de Uruguay,
Argentina, Chile, Colombia”. Además, otra estudiante del mismo nivel agregó: "No tenemos tanto acceso a esas informaciones, por supuesto también en la escuela nosotros no somos estimulados a tener informaciones sobre esos pueblos".

La mayoría de las asociaciones con nuestra región provienen de las informaciones suministradas por los medios de comunicación masiva y los de entretenimiento. Todavía persiste la idea difundida durante los años de las guerras civiles, de ser una región violenta, insegura y peligrosa, así lo manifestaron varios estudiantes. "Para nosotros América Central es más conocida por las playas, la gente, por la fiesta, es un lugar más turístico, y, sí, infelizmente lo que los periodistas dicen siempre está relacionado con la violencia y la inseguridad".

Los estudiantes hablantes nativos del español, de diferentes orígenes suramericanos, tampoco tenían muy claros los aspectos relacionados con Centroamérica, aunque lograron identificar los nombres de algunos países. Por ejemplo, una estudiante de nacionalidad argentina, con 20 años de residir en Brasil, expresó: "No sé nada de Centroamérica, lo único que sé es lo que recuerdo de la escuela, y era que Cristóbal Colón había llegado a esa región. Y que todavía es una zona donde hay muchos indios". Sin embargo, tenían una idea positiva con respecto a la integración latinoamericana en aspectos políticos y económicos, por lo que le interesó saber más sobre el istmo.

Por otra parte, en conversación con estudiantes del nivel VII, una estudiante quien seguirá el camino de la enseñanza dijo no saber nada de la región, ni de los países y mucho menos 
de las manifestaciones artísticas en algún género; la única asociación fue con el baile y ritmo del reggaeton "tan relacionado" con los países de Centroamérica. Como se mencionó arriba, mucha de la información que los estudiantes tenían sobre Centroamérica provenía de los estereotipos difundidos por los medios de comunicación masiva. El tema de los estereotipos y prejuicios sobre la región fue abordado en el taller "Centroamérica, puente geográfico y cultural”.

En general, de las conversaciones con los estudiantes con respecto a las manifestaciones artísticas centroamericanas no se pudo obtener ningún dato. Los artistas mencionados fueron los siguientes: en el área de literatura, mencionaron haber leído algo de $\mathrm{Pa}$ blo Neruda, Mario Benedetti, Gabriel García Márquez y Julio Cortázar. En cine, las películas del español Pedro Almodóvar y algunas argentinas como Diarios de motocicleta. En artes plásticas, a la mexicana Frida Kahlo. En el caso de la música, solamente se enfocaron en la proveniente de la cultura pop, destacaron a Alejandro Sanz de España, y a algunos latinoamericanos como Shakira, Calle 13, Maná, Mercedes Sosa y Fito Páez.

En el caso de las profesoras de los cursos de la carrera de Licenciatura en Letras-Español, la situación no fue muy diferente a la de los estudiantes. En los cuestionarios aplicados contestaron algunas de las siguientes preguntas abiertas:

1. ¿Cuál variante de español aprendió?

2. ¿Qué obras literarias centroamericanas ha leído?

3. ¿Qué películas centroamericanas ha visto?
4. ¿Conoce a algún cantante o grupo musical centroamericano?

5. ¿Hay en su plan de estudios algún curso que incluya la cultura y arte de Centroamérica?

6. ¿Le interesaría impartir un curso que abordara la cultura y arte centroamericano?

En el caso de la profesora Teixeira Saldanha, quien imparte los cursos en el área de la lingüística aplicada, aprendió la variante rioplatense y con respecto a la producción artística de la región no conoce ninguna obra o artista. Desconoce si en el plan de estudios hay un curso que incluya temas de Centroamérica. Con respecto a la pregunta 6 apuntó: "Sí, sería muy interesante, es una lástima que el tiempo sea tan corto para dar cuenta de tantos contenidos previstos por los documentos oficiales. Me encantaría saber más sobre Centroamérica y poder compartir con más alumnos tan bellas riquezas culturales, literarias, gastronómicas, etc.”.

La profesora Parrini imparte los cursos en el área de la lingüística aplicada. Ella no aprendió una única variante del español, sino varias, pues tuvo profesores de España, México y Suramérica, y compañeros de clase de diferentes países. Ha leído textos de Rubén Darío y Rigoberta Menchú. Piensa que no existe un curso que incluya aspectos culturales de Centroamérica. Con respecto a la última pregunta, añadió: "En este momento, no. Primeramente, necesito conocer mejor las culturas centroamericanas".

Por otra parte, la profesora Oliveira enseña cursos de lingüística aplicada. Ella no aprendió una variante específica de español, pero sí reconoce que tuvo 
más influencia del español rioplatense. Dijo conocer casi nada de obras y artistas centroamericanos, pero aunque en el plan de estudios no hay un curso que se enfoque sobre la región, ella toca en sus clases aspectos sobre las guerras civiles y dictaduras, especialmente por medio de los textos de Rigoberta Menchú y la película mexicana Voces inocentes sobre la guerra civil en El Salvador. Sobre la última pregunta afirmó: "Sí, es importante conocer un poco de la cultura y la historia de los territorios hispanohablantes, las características compartidas y las diferencias".

Finalmente, la profesora Hernando imparte los cursos de literatura, la variante de español que maneja es la peninsular y la mexicana. Entre los autores que conoce y que ha leído destacan Miguel Ángel Asturias, Roque Dalton, Manlio Argueta, Augusto Monterroso, Ernesto Cardenal y Rodrigo Rey Rosa. Desconoce música, plástica y cine de la región. En los cursos de literatura que ella imparte, incluye contenidos de la región, por ejemplo, en el curso de Literatura Hispánica I se lee y estudia el Popol Vuh y el Chilam Balam. En el curso de Literatura Hispánica III, se estudia a Asturias y Monterroso.

De la pregunta 6 explicó lo siguiente: "Sí, me parece importante abordar la cultura centroamericana, porque es una parte integrante de América Latina que es necesario que sea conocida por los estudiantes. No plantearía esta inserción como monográfica sino integrada en discusiones más amplias que abarcasen la producción latinoamericana, desde diversos enfoques, como, por ejemplo, la novela de dictadura, la actualidad de las literaturas indígenas, el tema de la migración".
En síntesis, el conocimiento sobre la región centroamericana de los estudiantes de la carrera Licenciatura en Letras-Español y de las profesoras que imparten los cursos es mínimo; sin embargo, hay interés por recibir más información.

\section{Conclusiones}

De la información extraída por medio de los cuestionarios y entrevistas aplicados a los estudiantes y profesoras, se encontraron los siguientes hallazgos: todavía la variable dialectal más apreciada por los docentes es la de España. Es decir, se sigue privilegiando lo europeo sobre lo hispanoamericano, a pesar de la variedad lingüística y cultural de nuestro continente. Por otra parte, se puede constatar que el conocimiento general sobre la región centroamericana por parte de los estudiantes de la carrera de Licenciatura en Letras-Español del Departamento de Lenguas y Literatura Extranjeras (DLLE) de la Universidad Federal de Santa Catarina (UFSC) es mínimo, así también, el de las profesoras que imparten los diferentes cursos en el área de Lingüística y Literatura.

Según lo observado, podría señalar varias de las razones que permitirían explicarlo. La primera de ellas sería la lejanía geográfica e histórica; Brasil en el pasado tuvo un desarrollo desligado de los otros países suramericanos hispanos. Por esta razón, en el sistema educativo público, se privilegiaba la enseñanza de lenguas como el italiano, alemán, polaco, entre muchas otras que llegaban con los inmigrantes europeos.

La situación comenzó a cambiar con la creación del Mercosur en la década 
de los años noventa. Además, del establecimiento del español y el portugués como lenguas oficiales según el artículo 46 del protocolo de Ouro Preto. Así también el país suramericano ha logrado convertirse en una economía importante a nivel mundial y en el líder a nivel latinoamericano en materia económica y geopolítica. Ha dejado de estar de espaldas sus vecinos, hispanohablantes.

Por primera vez de una manera más efectiva e institucionalizada, se incorporó la enseñanza del español en el sistema educativo brasileño. Se hizo popular y atractivo por diferentes razones, desde motivaciones laborales hasta el gusto por una lengua hermana del portugués, que siempre estuvo al otro lado de las fronteras, pero que había sido opacada por la enseñanza de otras lenguas europeas.

En los primeros años del siglo XXI, había una preocupación por destacar lo hispánico y lo hispanoamericano, por ejemplo, el Ministerio de Educación y de Cultura de Brasil en conjunto con la Embajada de España en ese país, publicaba cada año un anuario sobre asuntos hispánicos en el que se abordaban temas variados con respecto a la enseñanza del español, la historia en común de las lenguas y culturas lusa e hispánica, la literatura, la producción de materiales didácticos entre otros.

Sin embargo, ese reciente interés por lo hispanoamericano, se enfoca en los países hispanos fronterizos con Brasil y en los aportes de la cultura, literatura y escritores mexicanos. No se hace una diferenciación geográfica con respecto a la parte hispanoamericana, por lo que no es muy claro, si se incluye o hacen estudios a la cultura centroamericana, pues no se encontró ninguna referencia al respecto.
Aunque Centroamérica es una región con buenas producciones artísticas en los diferentes géneros, es muy difícil que estas, salvo excepciones, puedan trascender las fronteras del istmo por razones ligadas a lo económico o bien al desconocimiento de estos territorios. Los países suramericanos tienen una fuerte estructura económica y de difusión del arte, además de una larga tradición de organizaciones e instituciones ligadas a la producción e internacionalización de sus obras artísticas. Aún en la era del internet, pues en este caso no se trata de la distancia sino de acceso.

El término "Centroamérica" es asociado normalmente a las islas del Caribe, países como: Puerto Rico, Cuba y República Dominicana y, por tanto, los centroamericanos serían solamente "caribeños". Lo anterior se comprobó durante la realización de los talleres didácticos en los cuales se discutieron los conceptos anteriores. Los estudiantes de la carrera de español se autodefinieron como "brasileños" y como "latinos" a las personas de otras nacionalidades que tienen como lengua materna el español.

Por otra parte, es interesante el concepto de Brasil como potencia regional en ascenso, aparte de liderar económicamente el Cono Sur, en el aspecto socio-cultural; tal vez de una manera no consciente, sino heredada de la historia que tuvo, hay una idea generalizada de que es uno y separado de América Latina, concepto utilizado solamente para referirse a los países hablantes de español y, con frecuencia, suramericanos. No hay asociado un sentimiento fuerte de identidad latinoamericana, de pertenecer, de ser parte de este subcontinente; su identidad fue marcadamente brasileña. 
Por otra parte, al principio del proceso investigativo, con respecto a la región centroamericana, se notó una idea de "exotismo", marcado por la distancia, el desconocimiento y la deformación difundida por los medios de comunicación, como un lugar, "un país" y no varios, peligroso, pobre y violento, por las secuelas de las guerras de las décadas pasadas, por la presencia de carteles de droga y pandillas. Además, de ser visualizado como un destino turístico, de fiesta, deportes de aventura y de bailes sensuales.

Sin embargo, durante el proceso, estas ideas fueron modificándose paulatinamente, a través de las conversaciones, discusiones, talleres didácticos y acercamiento a las obras artísticas. La respuesta de los estudiantes hacia la región "desconocida" fue muy positiva. A partir de las diferentes obras artísticas, hubo una identificación con su temática y las preocupaciones, luchas y sentimientos no fueron tan diferentes de los de su propia realidad. Al mismo tiempo, las profesoras que imparten los cursos de la carrera se mostraron entusiastas con la información y acercamiento a los temas y problemas de la realidad centroamericana mediante obras artísticas.

Finalmente, como visión prospectiva, es de vital importancia continuar con procesos de acercamiento e intercambio de conocimientos con centros universitarios brasileños, para identificar la región centroamericana como un espacio importante en lo geopolítico y económico. Además, de la difusión y promoción de los aspectos culturales y artísticos producidos en la región y que son de una gran calidad. El aporte de la investigación al programa Licenciatura en Letras-Español permitió acercar a los estudiantes y profesoras al conocimiento de la región centroamericana, en general desconocida, como se pudo confirmar. Se hizo una donación de recursos didácticos a la biblioteca del Departamento de Lenguas y Literaturas Extranjeras (DLLE). Esta consistió en parte de los textos literarios y audiovisuales utilizados en los talleres. Las profesoras se comprometieron a incorporar en adelante contenidos y temas relacionados con la cultura de Centroamérica.

\section{Notas}

1. Universidad Federal de Santa Catarina, página oficial: http://ufsc.br

2. El Marco Común Europeo de Referencia para las lenguas: aprendizaje, enseñanza, evaluación es un estándar europeo para la medición de las habilidades lingüísticas. Forma parte del proyecto general de política lingüística del Consejo de Europa, que ha desarrollado un esfuerzo por la unificación de directrices para el aprendizaje y enseñanza de las lenguas dentro del contexto europeo. El documento final fue elaborado por el Consejo de Europa y presentado en 2001 durante la celebración del Año Europeo de las Lenguas. En: http:// cvc.cervantes.es/ensenanza/biblioteca_ele/marco/presentacion.htm

3. En las actividades desarrolladas en los talleres se trabajaron textos de artistas centroamericanos. En poesía, destacaron los siguientes autores: Roque Dalton, Otto René Castillo, Ernesto Cardenal, Jorge Debravo, Gioconda Belli, Ana Istarú, Ana María Rodas, Shirley Campbell Barr. En cuanto a los textos musicales, se escucharon canciones de: Carlos Mejía Godoy, Fidel Gamboa, Guadalupe 
Urbina, Perrozompopo, Rubén Blades, entre otros. En la bibliografía, se pueden consultar los textos que se trabajaron con los estudiantes en los talleres.

4. Aclaro que en el Cuadro 2. Tres razones por las que los estudiantes deciden estudiar la carrera de español. La razón número 3 "porque es una lengua bonita al oído". Se refiere a la sensación auditiva que provoca en los lusoparlantes. Todas las razones fueron sistematizadas a partir de las conversaciones y las entrevistas informales con los estudiantes de los diferentes niveles del programa.

\section{Bibliografía}

Cuevas Molina, R. (2012). De Banana Republics a Repúblicas maquileras. La cultura en Centroamérica en tiempos de la globalización neoliberal (1990-2010). San José: Editorial de la Universidad Estatal a Distancia.

Eres Fernández, G. (2000). La producción de materiales didácticos de español como lengua extranjera en Brasil. Anuario brasileño de estudios hispánicos. Suplemento $E l$ hispanismo en Brasil. Consejería de Educación y Ciencias en Brasil. Brasilia: Embajada de España.

García Morejón, J. (1990). "Creación y desarrollo del hispanismo en Brasil". Suplemento El Hispanismo en Brasil. Anuario brasileño de estudios hispánicos. Embajada de Brasil, pp. 18, 19. En: www.mecd. gob.es/dms-static/861125a2.../ brasil/...y.../abeh2000s.pdf

Granados Chaverri, C. (1985) Hacia una definición de Centroamérica: el peso de los factores geopolíticos. Anuario de Estudios Centroamericanos.
San José, C.R.: Universidad de Costa Rica.

Guberman, M. (1990). La enseñanza de la literatura hispanoamericana en Brasil. Suplemento El hispanismo en Brasil. Anuario brasileño de estudios hispánicos. Embajada de España en Brasil. En: www.mecd. gob.es/dms-static/861125a2.../ brasil/...y.../abeh2000s.pdf

Hernández Sampieri, R. (2010). Metodología de la investigación. México D.F.: Interamericana Editores.

Hymes, D. (1974). Hacia etnografías de la comunicación. En Antología de estudios de etnolingüística y sociolingüistica. México D.F.: UNAM.

Kawamoto, D. y Eres Fernández, G. (2012). "La difusión de la lengua española en Brasil: de sus primeros pasos a su inclusión en el Enem". En revista digital Eutomia, 10, p. 283.

Littlewood, W. (1998). La enseñanza comunicativa de idiomas. Introducción al enfoque comunicativo (Trad. Fernando García Clemente). Madrid: Cambridge University Press.

Marco Común Europeo de referencia para las lenguas: aprendizaje, enseñanza, evaluación (2002). Coeditan: Secretaría General Técnica del MECD-Subdirección General de Información y Publicaciones, y Grupo ANAYA, S.A. En: https:// cvc.cervantes.es/ensenanza/biblioteca_ele/marco/cvc_mer.pdf

Nascimiento, S. (s.f.) La gente de Brasil: la enseñanza de español lengua extranjera para estudiantes brasileños, pp. 183-194. En: https://dialnet.unirioja.es/servlet/ articulo?codigo $=3210607$

Protocolo de Ouro Preto. Protocolo Adicional al Tratado de Asunción 
sobre la Estructura Institucional del MERCOSUR. Brasil, Argentina, Paraguay y Uruguay, 26 de marzo de 1991. En: http://www.rau. edu.uy/mercosur/opretosp.html

Pulido Tirado, G. (2010). Aportaciones teóricas de los Estudios Latinoamericanos. En Revista de la Teoría de la Literatura y Literatura Comparada Cuatrocientos cincuenta y dos grados Fahrenheit, p. 54. En: http://www.452f.com/es/genarapulido.html

Taylor, S. y Bogdan, R. (1986). Introducción a los métodos cualitativos de la investigación. Buenos Aires: Paidós.
Universidad Federal de Santa Catarina (página oficial). En: http://ufsc.br/

Wells, G. y Mejía, R. (s.f.). Hacia el diálogo en el salón de clases: enseñanza y aprendizaje por medio de la indagación, revista Separata Sintética. En: http://portal.iteso.mx/portal/page/portal/Sinectica/Gestion del_conocimiento/Ensayos $/ 26 \% 20$ Wells-Mejia-Separata.pdf

Zanón, J. (1999). La enseñanza del español mediante tareas. Español Lengua Extranjera 2. Madrid: Editorial Edinumen. 
